\title{
O drama como proposta metodológica para contribuição crítica e social do educando
}

Gilmar Magalhães

Robson Rosseto

Recebido em 22/03/2018

Aprovado em 21/06/2018 
Este artigo busca examinar a metodologia do Drama, fundamentado nos estudos de Beatriz Cabral, com vistas ao desenvolvimento do educando em sua formação crítica e social. Um processo dramático foi desenvolvido, com base na obra clássica Romeu e Julieta de William Shakespeare com uma turma de adolescentes em situação de vulnerabilidade social. A proposta utilizou especialmente duas estratégias do Drama para o envolvimento dos participantes: professor-personagem e estímulo composto. Ao longo da experiência, constatou-se a importância de o professor propor desafios e criar novos espaços criativos que propiciem o engajamento do educando, bem como o potencial pedagógico do Drama para a construção de um conhecimento crítico e reflexivo.

Palavras-chave: drama, professor-personagem, estímulo composto.

\section{INTRODUÇÃO}

A presente pesquisa tem como proposta refletir os procedimentos da metodologia do Drama na educação e a sua contribuição para o desenvolvimento social do educando no meio em que vive. A prática realizada foi desenvolvida com uma turma de 16 educandos do Instituto Salesiano de Assistência Social- ISAS1', com faixa etária entre 13 e 17 anos de idade.

A dramaturgia Romeu e Julieta de William Shakespeare foi selecionada, com destaque para a história de amor que envolve um casal de jovens apaixonados proibidos de vivenciar sua experiência amorosa mediante a rivalidade de suas famílias. A delimitação do processo dramático pela obra Romeu e Julieta foi

\footnotetext{
1 Instituição social, situada na Rua Santa Catarina, n 1750, bairro Guaíra, na cidade de Curitiba. A entidade visa o desenvolvimento integral e o fortalecimento de vínculos afetivos dos adolescentes participantes, com atividades artísticas, socioeducativas e recreativas, disponibilizadas no contra turno escolar. Para mais informações acessar: http://www.dombosco.net/comunidade/curitiba-isas/

$2 \mathrm{O}$ desenvolvimento prático da pesquisa foi realizado por mim, professor responsável da turma de adolescentes selecionada, sob a orientação do orientador, professor Dr. Robson Rosseto.
} 
associada ao envolvimento do participante através da estratégia do estímulo composto, sistematizada pelo pesquisador John Somers (2011), definido como um conjunto de diferentes artefatos, contendo fragmentos de texto, imagens de época, objetos e documentos envelhecidos, dentre outras possibilidades.

O pressuposto desta investigação é que se metodologia do Drama tiver ressonância no interesse dos participantes, o engajamento poderá criar possibilidade de que algo Ihes aconteça, contribuindo assim, com a sua capacidade de agir com autonomia e responsabilidade na interação com a sociedade. A opção pela proposta metodológica do Drama, desenvolvida com adolescentes em situação de vulnerabilidade social surgiu ao pensar o papel do professor, a partir do seguinte pensamento de Paulo Freire: "Ensinar não é transferir conhecimento, mas criar as possibilidades para a sua produção ou a sua construção." (1996, p.21)

O Drama como método de ensino, desenvolvido na Inglaterra, investigado no Brasil a partir dos anos de 1990, especialmente por Beatriz Cabral, tem origem anglo-saxônica e foi desenvolvido por Cecily O'Neill, cujo significado está relacionado ao termo process drama, também conhecido como drama in education. Segundo Cabral, trata-se de "[...] uma atividade de construção da narrativa teatral em grupos, onde o diretor, professor ou coordenador assume o papel de dramaturgo, intervindo na cena na medida em que propõe ações [...]" (2007, p. 48). De fato, é

[...] um processo de investigação artística e pedagógica que possui o potencial de proporcionar apropriação da linguagem cênica e a exploração de questões e problemas acerca da vida social e das relações humanas, oferecendo ao indivíduo a oportunidade de definir e clarificar sua própria cultura. É uma atividade criativa que se desenvolve em grupo e evoca uma atmosfera dramática que permite aos participantes vivenciarem uma experiência estética. (CABRAL e VIDOR, 2013, p. 18)

O Drama desenvolvido nos espaços pedagógicos é uma atividade dramática alicerçada em um contexto ficcional, explorada por meio da improvisação. O método, de caráter processual, impulsiona os sentimentos e o intelecto dos participantes, que requer constante negociação com o propósito de compreender os sentidos e os impactos dos acontecimentos 
cênicos vivenciados. Como processo, o Drama articula uma série de episódios, a partir de um pré-texto que delimita e potencializa a construção da narrativa teatral em grupo.

Diante de tal concepção, perguntou-se na pesquisa realizada: como as estratégias do Drama podem atrair/seduzir o indivíduo ao ponto dele se envolver e experimentar uma vivência estética? É possível o professor transitar entre o papel de artista e educador dentro de uma instituição de ensino? Essas indagações nortearam a proposta com base nos princípios do Drama, desenvolvida em três encontros de 4 horas cada. 0 processo dramático realizado com os educandos utilizou a obra Romeu e Julieta como pré-texto ${ }^{3}$, sendo a base de apoio para o processo, o fio condutor, na medida em que sugeriu papéis, obstáculos, tramas e o caminho a ser percorrido para a construção da narrativa a partir do improviso. No primeiro encontro, dias antes da proposta do Drama ser lançada para os educandos que participaram do processo, entreguei em mãos uma carta convidando-os a participarem da vivência cênica. A escrita continha fragmentos da seguinte citação:

A experiência requer que algo nos Aconteça ou nos Toque e isso requer parar: Parar para Pensar, parar para o Olhar, parar para Escutar, pensar mais Devagar, olhar mais Devagar, escutar mais Devagar; parar para Sentir, se ater mais nos Detalhes, suspender a opinião, suspender o juízo, suspender a vontade, suspender o automatismo da ação, cultivar a Atenção e a Delicadeza, Abrir os Olhos e os Ouvidos, falar sobre o que nos Acontece, aprender a Lentidão, aprender a Escutar os outros, cultivar a arte do Encontro, calar muito, ter Paciência e dar-se Tempo e Espaço. O Sujeito da Experiência tem paixão, ele Sente, Sofre, Padece e Se Transforma. Ele é Passivo, Receptivo, mas não quer dizer que não aja, um agir calmo e coerente, com sabedoria. A Experiência é uma abertura para o desconhecido, para o que não se pode antecipar nem 'pré-ver', nem 'pré-dizer'. (BONDÍA, 2002, p. 24)

\footnotetext{
${ }^{3}$ Segundo Beatriz Cabral o "Pré-Texto refere-se ao entendimento de que um texto literário, imagético, temático (coletânea de fragmentos sobre um mesmo tema) - deve figurar como pano de fundo para orientar as opções do diretor e/ou professor durante o processo de montagem ou investigação artística." (2007, p. 48)
} 
Ao apresentar trechos do texto de Jorge Larrosa Bondía, convidei-os a estar disponíveis para criar a possibilidade de que algo Ihes passasse, Ihes acontecesse e lhes tocasse, pois segundo o autor a experiência requer um gesto de interrupção. Após a entrega da carta cada qual fez a sua leitura e o tema gerou questionamentos entre os educandos. As perguntas acerca do texto de Bondía começaram a surgir e me coloquei no papel de mensageiro com a incumbência de entregar-lhes a carta, sendo assim, as suposições e reflexões acerca do contexto ficcional ficaram por conta deles. A carta também trouxe pistas que despertaram curiosidade, tais como: o desenho de um brasão, o ano de 1595, uma parte do texto escrito na língua italiana ${ }^{4}$, um papel envelhecido e o envelope lacrado com cera. A carta, além de convidá-los para vivência e trazer algumas pistas, foi um fator de motivação que instigou os educandos a quererem participar da proposta.

A condução do processo dramático ocorreu a partir da estratégia metodológica do Drama, chamado de teacher in role e traduzido por Professor-personagem, por Beatriz Cabral (2006). A estratégia propõe a atuação do docente enquanto Professorpersonagem, uma atuação assumida intencionalmente em sala de aula, como coautor da cena desenvolvida. O Professor-personagem é a mediação na qual o professor assume personagens durante a criação do processo narrativo, com o objetivo de estimular os estudantes a entrarem no contexto da ficção. Este procedimento exige que o professor atue como ator na atividade docente, contribuindo com um processo de ensino-aprendizagem mais participativo, pois esta proposta é um forte estímulo para o educando engajar-se no processo cênico. Nessa perspectiva,

O professor, através da representação de um personagem durante o processo, favorece a aproximação do aluno à literatura através da materialização do texto pela sua atuação, abrindo perspectivas de introdução da linguagem teatral de forma lúdica e surpreendente para os alunos. (VIDOR, 2012, p. 107)

${ }^{4}$ Ordinate Sua Maestà il Re (q. D.g) ha l'onore di evitare AV Escenica per vivere un'esperienza che Escenica, verificata in stanze reali of Instituto Salesiano, il $28^{\circ}$ giorno di atual, a 13h. 159510 di Julio Palace. 
No segundo encontro, os educandos foram recepcionados pelo Professor-personagem caracterizado com figurino do século XVI, representando o dramaturgo William Shakespeare (Figura 1).

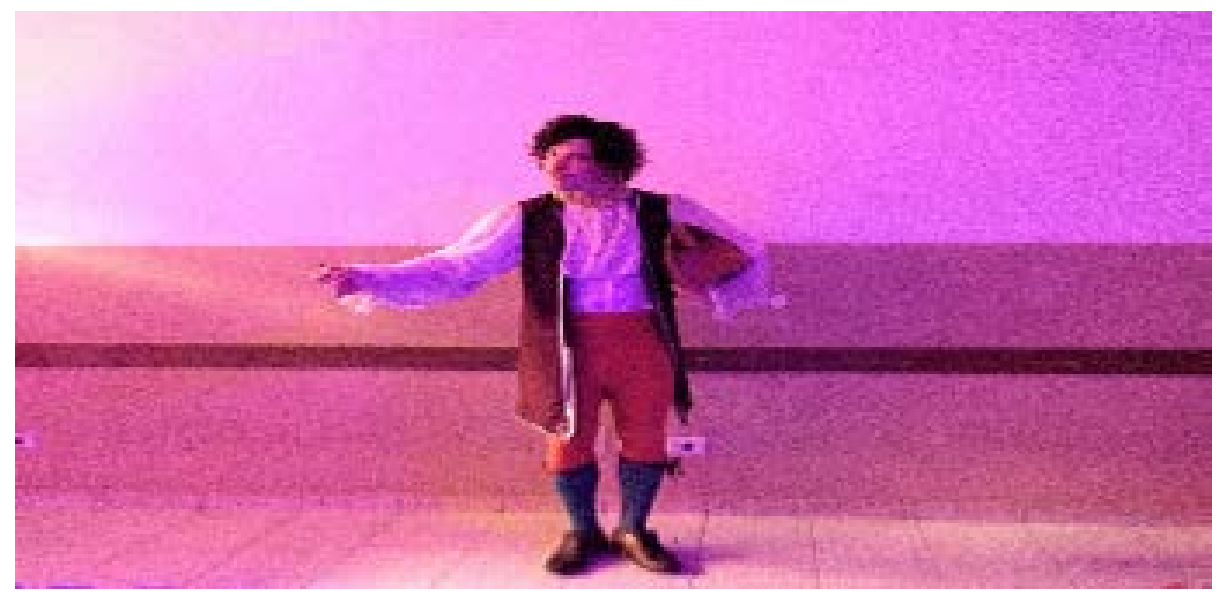

Figura 1 - Professor-personagem. Fonte: Felipe Segat (2017)

A sala de aula foi ambientada com pouca luz, lustre de velas no teto e música renascentista. Na primeira parte do encontro, o Professor-personagem encenou um fragmento do primeiro ato da dramaturgia de Romeu e Julieta sem que os participantes soubessem de qual texto dramático se tratava. 0 trecho que versa a história de disputas entre as duas famílias foi o ponto de partida para que os estudantes continuassem a criação da narrativa cênica. Em seguida, os participantes se dividiram em dois grupos, sendo um intitulado como "Grupo do duelo", e outro como "Grupo do baile". O grupo do duelo se deslocou para outro espaço, recebendo adereços como espadas, um pacote de bexigas, pó colorido, tecido de cores diferentes e uma tesoura. Os referidos adereços serviram de estímulo para criação de uma cena de duelo improvisada. O grupo do baile permaneceu na mesma sala, na qual a música renascentista estava compondo o ambiente. E para o desencadeamento dramático, o grupo recebeu máscaras, 
figurinos do século $\mathrm{XVI}$ e um pergaminho com um trecho do texto dramático original, contendo o relato do primeiro encontro de Romeu e Julieta.

Os referidos artefatos incentivaram a participação ativa dos educandos na construção da proposta cênica. O grupo do baile criou uma coreografia e encenou o encontro do casal em uma determinada parte da dança. O Grupo do duelo criou uma cena de enfrentamento entre duas gangues, na qual todos morreram com exceção de uma mulher. Os estudantes criaram, propuseram e vivenciaram por meio da improvisação cênica, como se estivessem em outra situação ou lugar, assumindo papéis de personagens. Cabe destacar que a improvisação teatral é uma prática importante na metodologia do Drama, segundo Robson Rosseto "Improvisar é criar, jogar, arriscar, transformar uma ideia num espaço privilegiado para a concepção poéticas e simbólicas. No âmbito do ensino, esse fazer pode desencadear processos de aprendizagens que contribuem para formação de sujeitos autônomos." (2013, p. 12) Baseado num processo de exploração e investigação, a proposta do Drama se utiliza da improvisação teatral, nos quais os educandos participam da criação de personagens e do enredo, fundamentada no pré-texto.

$\mathrm{Na}$ segunda etapa da aula, o Professor-personagem caracterizado de Shakespeare, encenou outro trecho da história, o $3^{\circ}$ ato da peça, momento em que o pai de Julieta a proíbe de relacionar-se com Romeu. Ao mesmo tempo, ele apresentou para os estudantes estímulos compostos, uma mala e uma maleta, quando relatou que esses foram os únicos vestígios deixados pelo casal de apaixonados. Alicerçados na trama de Romeu e Julieta, os participantes foram encorajados a entrar no mundo da ficção através da ambientação sonora, dos figurinos da época e dos objetos/estímulos contidos na mala e na maleta. Os materiais ofertados aos educandos para a investigação do tema proposto foram os seguintes: objetos da personagem Julieta (Figura 2), uma mala vermelha contendo um vestido, uma camisola, objetos de adorno pessoal, uma rosa seca, um bilhete de amor, um pequeno baú e dentro dele um colar, um frasco de vidro, um brasão, duas fotos e uma certidão de casamento. 


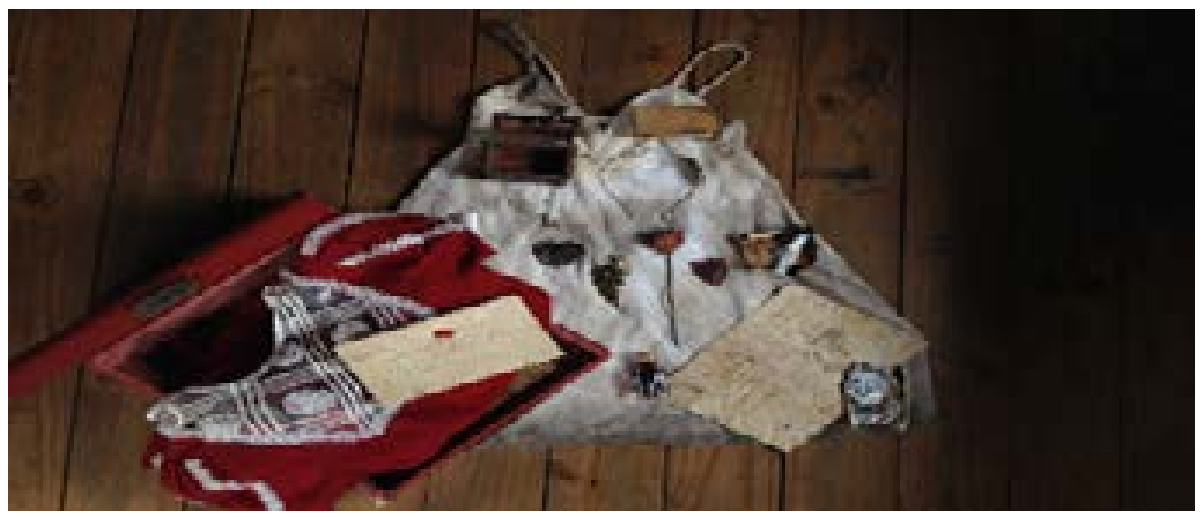

Figura 2 - Estímulo composto Julieta. Fonte: Gilmar Magalhães (2017).

No outro pacote de estímulos, objetos do personagem Romeu (Figura 3), uma maleta de couro contendo uma camisa, um brasão, um punhal, uma pena, uma pulseira de couro com uma cruz, um saquinho com uma pedra preciosa, um lenço feminino, duas fotos e um pequeno baú com um anel escrito a inicial da família.

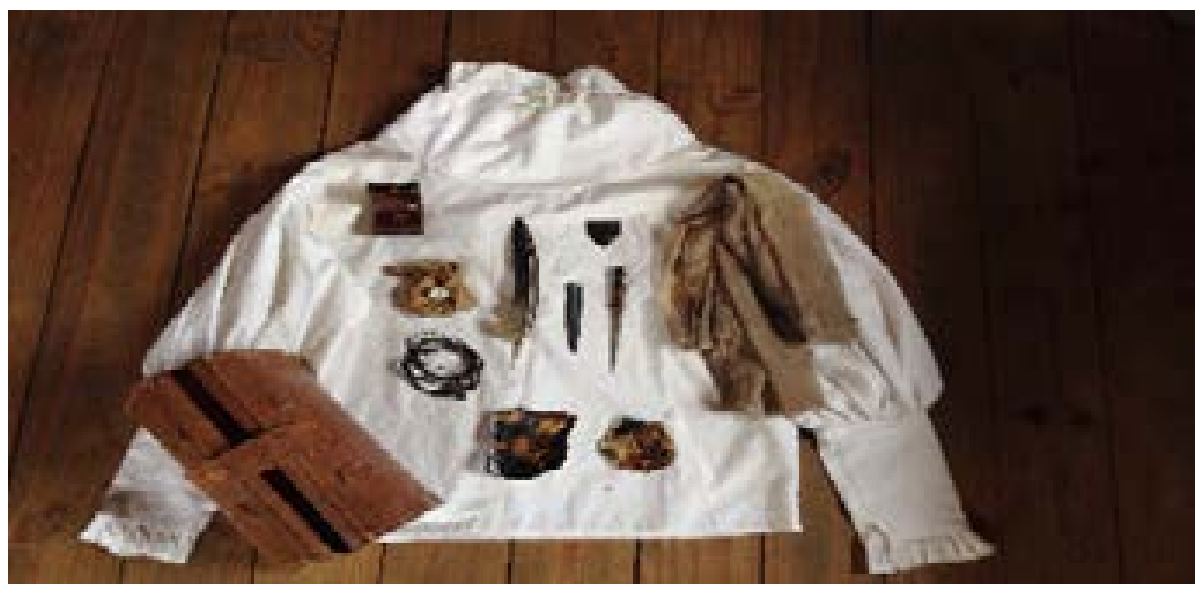

Figura 3 - Estímulo composto Romeu. Fonte: Gilmar Magalhães (2017). 
Uma atenção especial foi destinada para a construção dos objetos e dos documentos, confeccionados nos mínimos detalhes. O brasão foi produzido artesanalmente com um pedaço de lata velha, as roupas foram deterioradas com pó de café, as fotografias foram impressas em papel fotográfico e tiveram as bordas queimadas, a rosa foi deixada debaixo de sol e chuva para envelhecer naturalmente, os bilhetes e documentos envelhecidos por betume e a letra manuscrita foi elaborada com base na caligrafia da época, século XVI. A riqueza de detalhes dos objetos sugere a motivação para a ação dos participantes, além de incentivar as possibilidades de desenvolvimento da narrativa e imersão no contexto de ficção. Portanto,

A característica mais importante do pacote de estímulo, entretanto parece ser o envolvimento emocional do grupo com o tema. Se o cruzamento de artefatos, a história de origem do pacote e o seu foco dramático forem convincentes e esteticamente bem resolvidos, a atenção ficará concentrada nos conflitos subjacentes à trama, e será afastada a possibilidade de a ação se transformar em mera ilustração das situações sugeridas. (CABRAL, 2006, p.37)

Importante ressaltar que a dedicação do professor e o tempo empregado para preparar os materiais que irão compor o estímulo composto é fundamental para o envolvimento do educando, pois "Uma experiência bem sucedida não pode acontecer se os participantes não acham relevância no material explorado."(SOMERS, 2011, p.178) O estímulo composto tem o potencial de provocar um problema a ser investigado pelos participantes, fornecendo um potente apoio inicial para a criação da narrativa cênica, sendo um alicerce de orientação contínua no processo criativo.

Ao receber os pacotes de estímulos, a turma levantou possibilidades sobre os significados individuais de cada material (Figura 4). Em seguida os participantes se dividiram em quatro grupos, quando o processo criativo foi desencadeado pelas seguintes perguntas-chave: “Quem foram estas pessoas?" e "O que aconteceu com elas?". As respostas foram as mais diversas, porém o que mais chamou atenção foi a imersão dos educandos na investigação, ao ponto de se colocarem no lugar das personagens com base nos pacotes de estímulos. 


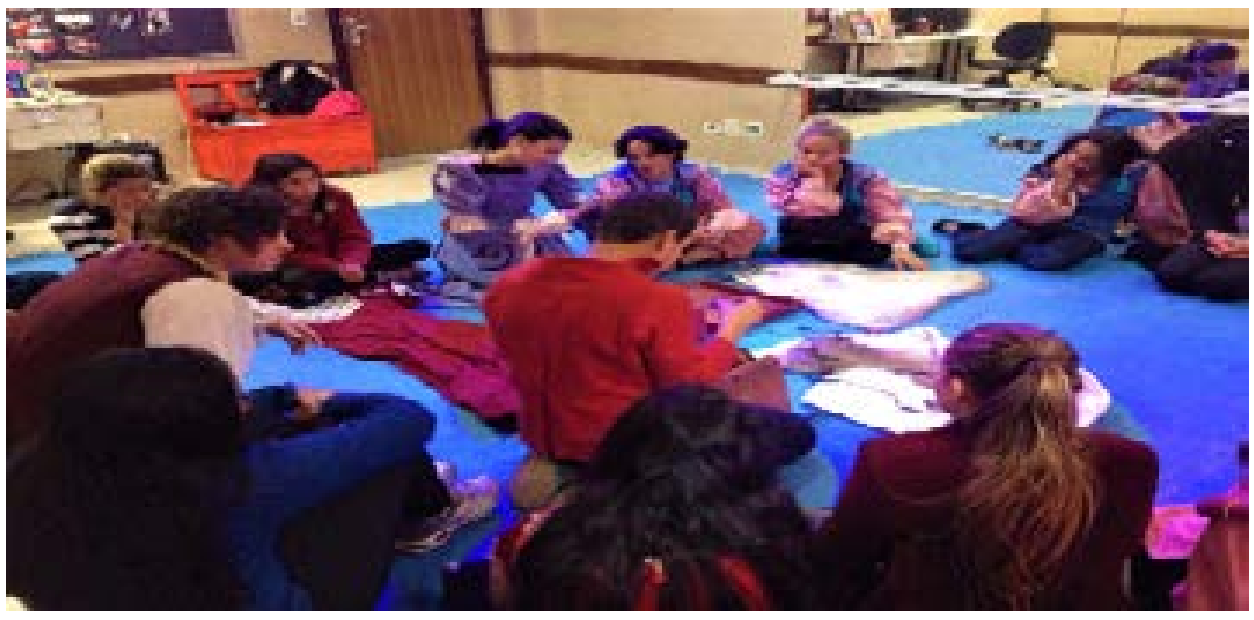

Figura 4 - Investigação. Fonte: Felipe Segat (2017)

Os integrantes de cada grupo conversaram entre si, motivados e desafiados pelo Professor-personagem, resolveram o problema dos personagens envolvidos no prétexto e desenvolveram histórias improvisadas a partir da investigação dos objetos. Os grupos apresentaram uns para os outros, e logo após a apresentação de cada proposta dramática, questões foram levantadas sobre os personagens expostos nas cenas. A sugestão cênica mais discutida foi quando o pai de Julieta a mandou para um convento dias antes dela fugir para se casar com Romeu, momento em que a jovem se matou porque não podia viver ao lado da pessoa amada.

Na cena mencionada, os participantes refletiram acerca do tema suicídio e da atitude tomada pelo personagem do pai de Julieta. Alguns educandos trouxeram relatos pessoais, tendo como exemplo uma jovem de 16 anos: "Meu pai não deixa nem eu sair com as minhas amigas porque acha que eu vou me agarrar com os piás. Ele não confia em mim, já tentei conversar, mas ele é um grosso [...]". (2017) Outra educanda de 17 anos comentou sobre como pretende atuar no futuro ao ser mãe: "Quando eu for mãe um dia, eu quero escutar mais meus filhos, porque eles tem opinião, 
eles podem ser meus filhos, mas eles são pessoas e eles precisam ser escutados, têm opiniões próprias, são outras pessoas e precisam ser respeitadas." (2017) Desse modo, os estudantes examinaram e refletiram sobre as implicações da questão familiar em pauta, resolveram o problema de suas maneiras, a partir das seguintes ideias: enfrentando, conversando, engravidando, brigando, matando e fugindo.

Nesse contexto, por meio da experimentação, as práticas de improvisação contribuíram com a possibilidade dos participantes se depararem com questões da essência humana associadas com o texto dramático selecionado, como paixões, desconfianças, relacionamentos, traições e disputa de poder. O impacto desses assuntos ativou a imaginação deles e tornou-se presente na resolução dos conflitos dramáticos, apoiado nas suas referências pessoais. Nesse sentido, Rosseto (2013) afirma que os participantes criam empatia e incluem as histórias de vida por meio do jogo teatral, possibilitando a identificação do grupo com as situações apresentadas e suas ressonâncias com o contexto local.

O processo desenvolveu-se através de episódios, no qual os estudantes foram construindo, aos poucos, a narrativa cênica, mediada pela atuação do Professor-personagem. No terceiro e último encontro, a obra de Romeu e Julieta foi apresentada e discutida, sobretudo acerca da construção da narrativa sem o prévio conhecimento da dramaturgia. De acordo com os educandos, na medida em que a leitura do texto dramático estava avançando, eles constataram que o processo cênico desenvolvido estava estreitamente atrelado com a narrativa de Romeu e Julieta.

Os próprios educandos argumentaram que o fato deles não saberem qual era a dramaturgia, os pacotes de estímulos, a mala e a maleta, proporcionaram inúmeras possibilidades criativas e despertou sobremaneira a curiosidade. Ao longo do debate, os estudantes disseram que os conflitos apresentados no texto Romeu e Julieta permanecem relevantes e atuais, uma vez que os personagens desejam independência e liberdade para vivenciarem uma história de amor. British Council ${ }^{5}$ e a Royal Shakespeare Company, 
destacam o mérito das obras de Shakespeare, quando afirmam que elas podem ajudar jovens a ampliarem seus horizontes. Efetivamente, “Os jovens poderão explorar o vibrante mundo das peças de Shakespeare e descobrir novas ideias que permeiam suas obras, graças a temas que são tão relevantes para nós hoje como eram há 400 anos." (DEVANE et al, 2016, p.4)

A leitura da obra Romeu e Julieta de Shakespeare, a atuação do Professor-personagem, os figurinos da época, a sonoplastia, os adereços e a ambientação cenográfica contribuíram para a expansão das experiências estéticas. Assim sendo, o envolvimento significativo e contínuo do estudante com atividades artísticas, códigos culturais e experiências criativas colaboram para ampliar sua visão de mundo e construir suas próprias narrativas e histórias. Cabral destaca (2012) que a ação cultural, pelo âmbito do ensino, pode ser vista como a ação do professor que busca quebrar a reprodução de comportamentos e hábitos que impedem a ampliação do olhar e da percepção do estudante. Diante dessa concepção, a metodologia do Drama pode ampliar a significação da ação do professor dentro da sala de aula, especialmente no que se refere a quebra de barreiras culturais, que permite o cruzamento de diferenças, intervindo como espaço para trocas de saberes.

Após o término da vivência realizada, os educandos estavam ansiosos para saber o que realmente havia acontecido com o casal, entretanto a pergunta que mais chamou atenção foi a de uma educanda de 14 anos: "Prof. esses objetos foram mesmo de alguém?" (2017)
A ênfase no sensorial e no engajamento emocional leva à busca de estratégias que deem visibilidade e permitam o envolvimento pessoal e físico com a intertextualidade da narrativa em processo. A apropriação e reconstrução da narrativa, pelos participantes, implicam sua atualização para questões que Ihes sejam significativas, a incorporação da dimensão pessoal, a possibilidade de refletir sobre seus significados ocultos, padrões de comportamento e aspectos da identidade. (CABRAL, 2007, p. 49)

\footnotetext{
${ }^{5}$ O British Council é uma organização internacional do Reino Unido, encarregada na difusão do conhecimento da língua inglesa e sua cultura, mediante atividades culturais e educativas. Para mais informações, acessar o endereço eletrônico: www.shakespearelives.org.br
} 
Com base no processo dramático desenvolvido, em função do engajamento emocional dos adolescentes, é possível afirmar que algo lhes tocou e este algo pode causar ressonâncias no meio em que vivem. É importante que os jovens aprendam por meio dos sentidos, da percepção, dado que o ser humano aprende por intermédio da experiência. Nesse sentido, a pedagogia teatral contribui na ampliação da visão de mundo dos participantes envolvidos e no entendimento do papel social do jovem na sociedade, bem como os mecanismos para a conscientização do seu próprio desenvolvimento dentro da coletividade.

A estratégia do Professor-personagem proposto por Beatriz Cabral, colabora no processo de interação e de mediação na relação professor e estudante, na ampliação dos seus horizontes, contribuindo na transição entre o papel de artista e educador dentro de uma instituição de ensino. Por sua vez, o estímulo composto é uma possibilidade metodológica imersiva, capaz de seduzir os participantes para o envolvimento necessário para uma experiência, com base em um conjunto de estímulos, os quais sugerem inúmeras possibilidades de criações, despertando assim a curiosidade dos participantes.

Tendo em vista os aspectos observados, é importante desordenar a relação professor-estudante, modificando os lugares que frequentemente ambos ocupam, desestabilizando as hierarquias, para permitir o cruzamento de fronteiras e a criação de espaços possíveis para a expressão das vozes, muitas vezes, silenciadas. A metodologia do Drama de um modo lúdico e improvisacional proporciona a imersão dos participantes envolvidos numa realidade imaginária fazendo-os viver por meio de personagens aquilo que está sendo criado simultaneamente com o processo de criação do drama.

A cada etapa do desenvolvimento dramático, a construção do conhecimento ocorreu em grupo, mediante reflexão das informações recebidas, decorrentes das situações criadas e mediadas pelo Professor-personagem. A eficácia desse método de ensino perpassa os aspectos estruturais e as suas estratégias garantem ao professor o exercício de escutar/perceber o estudante ao abrir oportunidades para que ele investigue as situações dramáticas baseadas em suas experiências. 


\section{REFERÊNCIAS}

BONDÍA, Jorge Larrosa. Notas sobre a experiência do saber e o saber da experiência. Revista brasileira de educação, Rio de Janeiro, n. 19, p. 22-28, jan. 2002.

CABRAL, Beatriz. Ação cultural e teatro como pedagogia. Sala preta, São Paulo, v. 1, n. 12, p. 4-17, jun. 2012.

. O professor dramaturg e o drama na pós-modernidade. Revista Ouvirouver, Uberlândia, n. 3, p. 47-56 jan./dez. 2007.

O Drama como Método de Ensino. São Paulo: Hucitec, 2006.

CABRAL, Beatriz; VIDOR, Heloise Baurich. MACBETH EM DRAMA: entre a performance e a representação. In: SILVEIRA, Fabiane Tejada da; FERREIRA, Taís; LEITE, Vanessa Caldeira (orgas.). Conversações sobre Teatro e Educação. Porto Alegre: Observatório Gráfico, 2013.

DEVANE, Sir Ciarán et al. Shakespeare vive nas escolas: material didático para professores. Trad. Fernanda Sampaio. British Council, 2016.

FREIRE, Paulo. Pedagogia da Autonomia: saberes necessários à prática educativa. São Paulo, SP: Paz e Terra,1996.

ROSSETO, Robson. Jogos e Improvisação teatral: perspectivas metodológicas. Guarapuava: Unicentro, 2013.

SHAKESPEARE, William. Romeu e Julieta. Trad. Bárbara Heliodora. Rio de Janeiro: Nova Fronteira, 1997.

SOMERS, John. Narrativa, Drama e Estímulo composto. Revista Urdimento, n. 17, p. 175-185, set. 2011.

VIDOR, Heloise Baurich. Macbeth apropriado: o texto em processos de teatro na escola via drama e professorpersonagem. Revista Ouvirouver, Uberlândia, v. 8, n. 1-2 p. 98108 jan./jun. - ago./dez. 2012. 